\title{
Thunderstorm Monitoring, Modelling, Response and Loading of Structures
}

\author{
Giovanni SOLARI*
}

The study of thunderstorms and their actions on structures is a dominant topic of recent research in wind engineering (Solari, 2014). This depends on the fact that methods used to determine wind actions on structures are still mostly based on the models for the stationary phenomena at synoptic scale that occur in neutral atmospheric conditions, with velocity profiles in equilibrium with the planetary boundary layer (PBL). Thunderstorms are non-stationary phenomena at meso-scale that occur in convective conditions with velocity profiles very different from those that are typical of the PBL. Design wind velocities with return periods greater than 10-20 years are often associated with thunderstorms.

The European project "Wind and Ports", carried out by author and his research group (Solari et al., 2012), offers a contribution to the growth of knowledge on thunderstorms. The project developed a monitoring network, the numerical simulation of wind fields, wind climate analysis and the implementation of algorithms for middle- (1-3 days) and short-term (0.5-2-hour) wind forecast in the ports of Genoa, Savona, La Spezia, Livorno and Bastia. A new project, "Wind, Ports and Sea", is currently financed by European Community to continue and extend the previous project (Burlando et al., 2014).

The monitoring network realized for "Wind and Ports" consists of 22 ultrasonic anemometers. Other 11 ultrasonic anemometers have been installed by local port authorities. In the framework of "Wind, Ports and Sea", 7 ultrasonic anemometers and 3 lidars are being installed. It is expected that a wind monitoring network composed by 40 ultrasonic anemometers and 3 lidars will be operational from the beginning of 2015 (Figure 1); other instruments, including thermometers, barometers and hygrometers, are being added to the anemometric network.

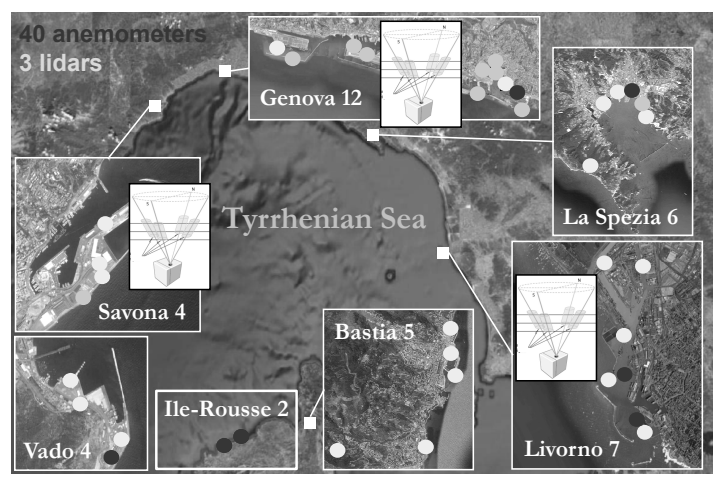

Figure 1 Wind monitoring network.

A set of servers placed in each port receives the measures, elaborates basic statistics on 10-min periods, and sends the information to the central server at DICCA. This server stores the raw data and the statistical values into a central dataset, after having systematically checked and validated the data. A procedure has been implemented (De Gaetano et al., 2013) to extract and separate different intense wind events. While literature tends to apply a binary separation of stationary Gaussian sinoptic events and non-stationary non-Gaussian

* Professor, Department of Civil, Chemical and Environmental Engineering (DICCA), University of Genoa 
thunderstorms, the registered data point out the existence of stationary non-Gaussian intermediate events that make the above separation a critical issue (Figure 2).

Each thunderstorm velocity record is decomposed into the the sum of its slowly-varying mean part, averaged on a 30-s moving average period, plus a residual fluctuation given by the product of its time-varying rms value by a random stationary Gaussian signal with zero mean and unit rms value. The main parameters of each record and its parts are collected and analyzed (Solari et al., 2014) to establish a realistic parameterized thunderstorm model. A model of the extreme wind velocity distribution of thunderstorms is in phase of study.

The dynamic response of structures to thunderstorms is evaluated by two alternative methods. The first is based on the Monte Carlo simulation of wind fields coherent with the above thunderstorm model. The second, oriented to engineering and code applications, applies an evolution of the response spectrum technique widely diffused in the seismic sector. This technique is first developed for single-degree of freedom systems subjected to perfectly coherent wind fields (Figure 3), then is extended to multi-degree of freedom systems subjected to partially coherent wind fields (Solari and De Gaetano, 2015).
The comparison between the results provided by the two methods points out an almost perfect agreement. The response spectrum technique leads to a straightforward definition of the equivalent static actions of thunderstorms.

The response spectrum technique and the equivalent static actions of thunderstorms are embedded into a new approach, referred to as the Independent Wind Loading Technique (Solari et al., 2013), aimed at establishing a new criterion for evaluating wind loading on structures in mixed climates. In place of the classical unique wind loading condition that joins different wind phenomena by mixed statistics, this technique gives rise to as many independent wind loading conditions as the wind phenomena that characterize the mixed climate, first of all synoptic and thunderstorm events.

This approach is robustly supported by the deep diversity of these events with reference to the stationary or non-stationary and Gaussian or non-Gaussian character of wind velocity, the shape of velocity profiles, the parameterization of wind fields with regard to roughness length and thermal stratification, the intensity, size, duration and frequency.

This remark on the different intensity, size, duration and frequency of synoptic and thunderstorm events points out that

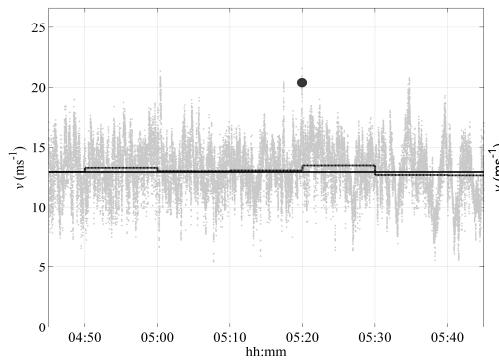

(a)

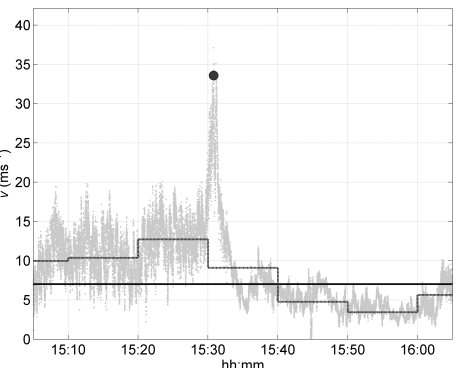

(b)

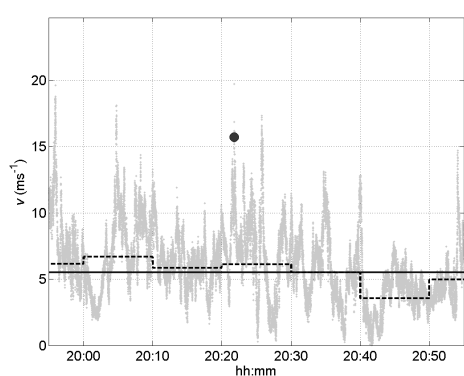

(c)

Figure 2 (a) synoptic event; (b) thunderstorm; (c) intermediate event.

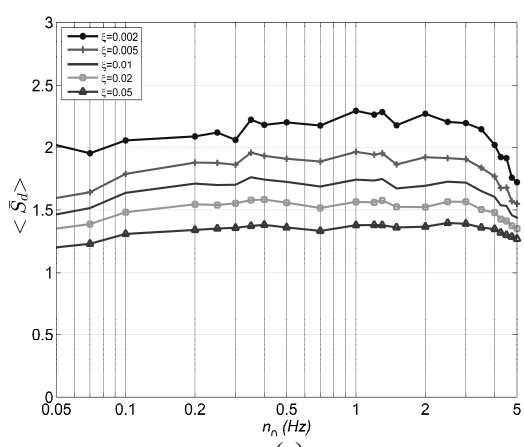

(a)

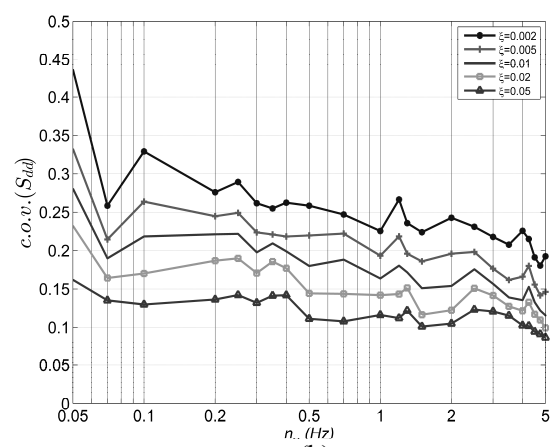

(b)

Figure 3 Mean response spectrum (a) and its coefficient of variation (b) as functions of the fundamental frequency $n_{0}$ and of the damping coefficient $\xi$. 
they do not lend themselves to be represented by the unique set of partial and combination factors usually adopted with reference to the classical unique wind loading condition. Diversifying this loading into a set of independent wind loading conditions leads to revisiting the actual combination rules of the loadings, at least introducing diversified sets of wind partial and combination factors (Solari, 2014).

\section{REFERENCES}

1) Solari G, Repetto MP, Burlando M, De Gaetano P, Pizzo M, Tizzi M, Parodi M, "The wind forecast for safety and management of port areas", J. Wind Eng. Ind. Aerod., Vol. 104-106, pp. 266-277, (2012)

2) Solari G, De Gaetano P and Repetto MP, "Wind loading and response of structures in mixed climates", Proc. 8 APCWE, (2013)

3) Solari G., "Emerging issues and new scenarios for wind loading on structures in mixed climates", Wind Struct, (in press)
4) De Gaetano P, Repetto MP, Repetto T, Solari G, "Separation and classification of extreme wind events from anemometric measurements", J. Wind Eng. Ind. Aerod., Vol. 126, pp. 132-143, (2014)

5) Burlando M, Repetto MP, Solari G, De Gaetano P, Pizzo M, Tizzi M, "Wind and waves numerical forecasting for safety access to port areas: the "Wind, Ports and Sea" project", Proc. 6 CWE, (2014)

6) Solari G, Burlando M, De Gaetano P, Repetto MP, "Characteristics of thunderstorms detected by the project Wind and Ports", J. Wind Eng. Ind. Aerod., (on submission)

7) Solari G, De Gaetano P, "Thunderstorm response of structures by response spectrum technique", Proc. 14 ICWE, (on submission) 